\title{
THE INHERITANCE OF HORNS AND FACE COLOUR IN SHEEP.
}

\author{
By T. B. WOOD, M.A., \\ Drapers' Professor of Agriculture in the University of Cambridge.
}

Ir is now four years since a preliminary note on the inheritance of horns and face colour in sheep was published in this journal ${ }^{1}$. The experiments then described have been continued each year, and a number of further interesting results have been obtained. The experimental work of the Agricultural Department of the University of Cambridge will be transferred this autumn from Impington to Gravel Hill, where it is proposed to begin a new series of sheep breeding experiments on somewhat different lines, bearing more directly on points of economic importance. Considerations of space are likely to make it impossible to continue the present experiments in addition to the new experiments which it is proposed to begin. They have indeed served their purpose, which was to study the possibility of experimental breeding with large animals on Mendelian lines.

The following pages, setting forth the results which have been obtained up to the present, make no claim to be a final pronouncement on the inheritance of horns and face colour. It is hoped however that they may be of general interest. They show clearly that segregation does take place, and at the same time indicate the kind of difficulties which anyone who proposes to work on Mendelian lines with large animals must be prepared to face.

\section{Description of parental types, the Dorset Horn and the Suffolk.}

The Dorset Horn breed has a pure white face and legs, with a pink nose, and, so far as could be ascertained, a complete absence of pigment in the skin'. It has a tuft of wool on the poll, which extends forward to

1 Vol. I. p. 364.

2 In some Dorsets there are black specks on the conjunctiva. 
about the level of the eyes. Both sexes have large horns, those of the male being larger and more spiral than those of the female (Plate $X$, Figs. 1 and 2).

The Suffolk breed has a pure black face, its head is quite bare of wool, and both sexes are normally free from horns (Plate $X$, Figs. 3 and 4). It is stated however that the occurrence of rudimentary horns, or scurs as they are called, is by no means unknown, even in pedigree flocks.

The experiment was begun in the antumn of 1903 by crossing a Dorset Horn ram with 30 Suffolk ewes. The reciprocal cross was made the next year by crossing a Suffolk ram with 20 Dorset ewes. The Dorsets used were bought as pure from well-known breeders. The Suffolk ram was kindly lent by $\mathrm{Mr}$ T. Goodchild. The Suffolk ewes were not registered, but they were from a flock which had been known for some years, and which had not produced either horns or white on the face or legs.

Description of the first cross, $F_{1}$. The first point to notice is that the $F_{1}$ animals are identical whichever way the cross is made. The lambs out of the Suffolk ewes by the Dorset ram could not be distinguished from those out of the Dorset ewes by the Suffolk ram.

In all $73 F_{1}$ lambs were bred. All of them had speckled faces and legs. The relative proportion of black and white varied considerably. There was a general tendency for the speckling to assume a "pattern," the black usually being densest on the end of the nose and round the eyes.

Of the 73 lambs 38 were males and 35 females. All the ram lambs showed obvious horns immediately after birth. Two were kept entire for breeding, one of which was accidentally drowned when about four months old. At this age his horn was exactly similar to the one ultimately used for breeding (Plate X, Fig. 5). The other ram lambs were castrated when quite young, after which their horns grew very little.

The $F_{1}$ ram shown in Plate $X$, Fig. 5, was used for two seasons, during which he served in all about 50 ewes. By that time his horns had attained the size shown in the photograph. Comparison with Plate X, Fig. 1, shows that neither in size nor shape are they the same as those of the Dorset parent. All the 35 ewe lambs (Plate X, Fig. 6) were carefully examined as lambs and none of them showed any sign of horns. Several died young, but 28 were kept for breeding. All of them when aged threw up small scurs (Plate XI, Fig. 7), which 
took the form of hard round knobs, firmly attached to the skull and about half an inch high.

From the above description it appears that there is no definite dominance of black over white or white over black. The inheritance of horns seems to be in some way related to sex, since the rams were horned and the ewes hornless except for the presence of scurs which appeared only in their second or third year. Horns therefore appear to be dominant in the male, recessive in the female. In making this latter statement however it must be remembered that only one $F_{1}$ ram was kept entire until adult, and his horns never attained the size or shape of those of the parent Dorset, and further that the $F_{1}$ ewes put up scurs when aged.

A certain amount of wool appeared on the poll and face of all the individuals of $F_{1}$, the amount being roughly intermediate between the two parental types.

The second generation, $F_{2}$. The $\mathrm{F}_{1}$ ram already described was mated with $28 \mathrm{~F}_{1}$ ewes, and the mating produced 33 lambs, as shown below.

$\begin{array}{ll}\begin{array}{l}21 \text { rams } \\ 7 \text { with large horns }\end{array} & \begin{array}{l}\text { 8 with no horns } \\ 7 \text { with round scurs }\end{array} \\ \begin{array}{l}\text { 1 with round scurs } \\ 4 \text { with loose scurs }\end{array} & 3 \text { with large horns }\end{array}$

The numbers given above are far too small to be expected to give an accurate Mendelian ratio. As far as they go however they are quite in accord with expectation, for the majority of the rams are horned, the majority of the ewes hornless, and this should be so if horns are dominant in the male and recessive in the female.

The seven $\mathrm{F}_{3}$ ram lambs described as possessing large horns were kept entire until they were about three months old, when their horns were all about the same size (Plate XI, Fig. 8). Only one was kept for stock. His horns when he was about 18 months old were almost indistinguishable from those of the $F_{1}$ ram (Plate $X, F i g .5$ ). The rest were castrated, or sold as fat lamb. The 10 ram lambs with scurs were also kept until three months old, when the difference between their scurs and the large horns described above was very apparent, as was also the difference between the two types of scurs. One type was like the scurs of the aged $F_{1}$ ewes, small round hard firmly attached knobs, the other being longer and thinner and so loosely attached that they were readily 


\section{Inheritance of Horns and Face Colour in Sheep}

movable (Plate XI, Fig. 9). Only one of the hornless rams (Fig. 10) was kept entire until fully adult. When 18 months old, after serving about 30 ewes, he was still quite free from horns or scurs. The other two were castrated when about three months old, or sold as fat lamb.

All the $\mathrm{F}_{2}$ ewe lambs were kept for breeding, most of them for several years. One of those with large horns died when about six months old. The other two are still alive. Their horns are similar to those of the $F_{1}$ ram, except that in the dark-faced ewe (Plate XI, Fig. 12) the pigment has extended to the horns. The ewe lamb with scurs died when about six months old. At this age her scurs had not increased in size to any appreciable extent. The hornless $F_{2}$ ewes were all kept for breeding. Two of them have grown scurs like those of the $F_{1}$ ewes. The rest are still, when over four years old, quite free from horns or scurs.

From the above statements it appears that the inheritance of horns is complicated by the fact that there are, so to speak, several degrees of hornedness : the large spiral horns of the parental pure Dorsets, the large horns of the $F_{1}$ rams and of the $F_{2}$ horned ewes which never attain the size or shape of the parental type, the small round scurs of the $F_{1}$ ewes and of some of the $\mathrm{F}_{2}$ rams and ewes, the thin loose scurs of some of the $\mathrm{F}_{2}$ rams, and finally the complete absence of horns of any kind. In view of these facts, and in the absence of satisfactory breeding tests of animals with scurs, it is necessary to modify the statement as to the inheritance of horns. Large horns are certainly dominant in the male and recessive in the female. The meaning of scurs must still be left undecided.

Turning now to face colour, the following figures show the distribution of face colour in $F_{2}$.

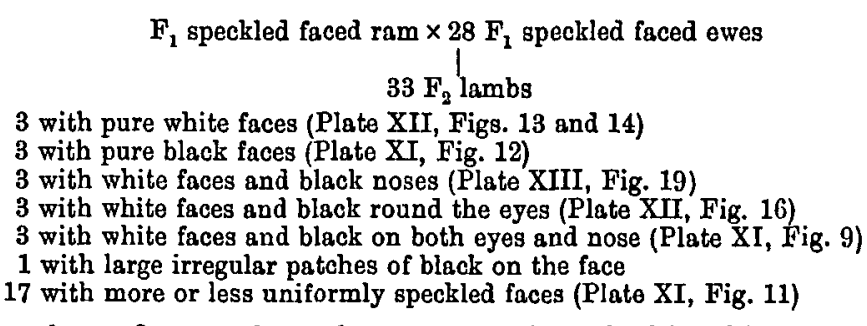

The above figures show that segregation of white, black, and speckled faces has taken place. But the case is evidently not a simple one. If it were a simple case of the speckled face being intermediate between the black face and the white face, then the ratio of the number of black faces to speckled faces to white faces should be $1: 2: 1$. The figures 
give a ratio of $1: 9: 1$. The numbers are too small for the ratio to carry much weight, but they are so far from the ratio expected that the difference cannot be ignored. Further the occurrence of so many different types of patterns in the faces of the $F_{2}$ sheep is a strong indication of the complexity of the black face, which seems to contrin at least three separate characters, black on the nose, black round the eyes, and black on the other parts of the face.

One further point must be noted here. It is evident from inspection of the photographs of the black faced $\mathrm{F}_{2}$ sheep, that their faces are apparently not so black as those of the parental Suffolk type. This is explained in great part by the fact that a black face has not yet been obtained free from wool like the face of the pure Suffolk. The wool does not carry pigment like the hair does, and it consequently masks the pigment of the hair and skin underneath it (Plate XII, Fig. 15). There is no reason to suppose that blackness is coupled with wool on the poll or face, for these characters are separate in the parents. Only three black faces were obtained in $\mathrm{F}_{2}$ : probably if the numbers had been larger, black faces free from wool would have been obtained, and would have looked a more satisfactory black than those shown in the photograph. It must however be stated that the pigmentation of the black faces obtained was not quite the same as that of the Suffolks: it showed a distinct tinge of brown.

Breeding tests of $F_{2}$ and succeeding generations. It has not been possible to test all the types described above. Most of them have however been tested and the results are given below.

Horned $F_{2}$ ram. This ram was mated with 6 pure Dorset ewes with the following result:

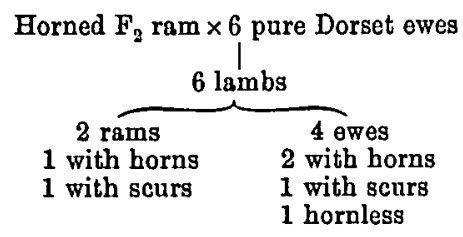

On the assumption that horns are dominant in the male, a horned $\mathrm{F}_{2}$ ram might be pure horned, or heterozygous as regards that character, the chances being two to one against any particular ram being pure. The appearance of a hornless lamb in the progeny of the ram under experiment out of pure horned ewes shows at once that he is not pure horned. This result is quite in accordance with the dominance of horns in the male. 


\section{Inheritance of Horns and Face Colour in Sheep}

Hornless $F_{2}$ ram. This ram was tested twice, once with hornless Hampshire ewes, the second time with $\mathrm{F}_{1}$ ewes. The results are given below :

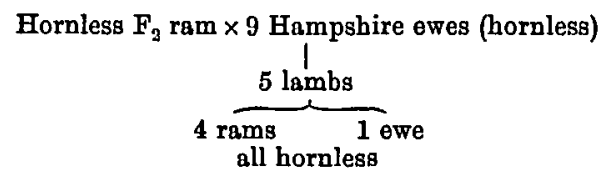

This is strong evidence that the ram was pure hornless: if he had been carrying horns there would certainly have been some sign of them in his male progeny.

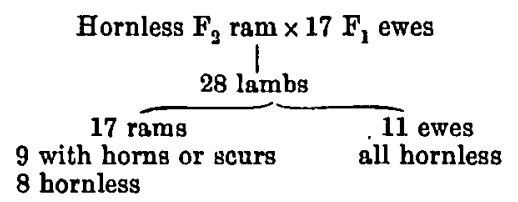

Among the progeny of a pure hornless ram and $F_{1}$ ewes, half the males should be horned, half hornless, and all the females should be hornless. The figures given above are quite in agreement with this expectation, which is based on the assumption that horns are dominant in the male and recessive in the female. The lambs were examined at the age of about two months. At that age eight were hornless. Only one was kept for stock (Plate XII, Fig. 18). He remained hornless until about two years old, when he threw up small scurs. By this time he had been mated with Suffolk ewes as follows:

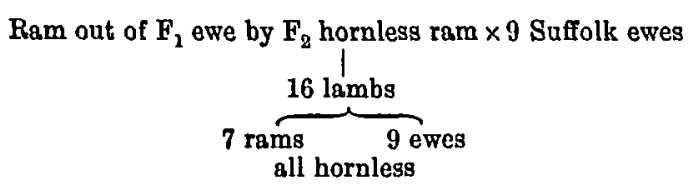

These lambs were hornless when they were sold as fat lambs. It is possible that some of them would have thrown up scurs when they became adult. It appears to be by no means rare for Suffolks to produce scurs when 18 to 24 months old.

Hornless $F_{2}$ ewes. The testing of ewes is obviously a slow and tedious process. A ram can be mated with a large number of suitable ewes and in one season produce a sufficiently numerous progeny to warrant a definite conclusion. But a ewe brings forth only one, two, or occasionally three lambs in a season, so that she must be bred from for several seasons before her purity or impurity as regards any character 
can be ascertained. The hornless $\mathrm{F}_{2}$ ewes were tested by mating them with the $F_{2}$ hornless ram (Plate XI, Fig. 10) already proved to be pure hornless.

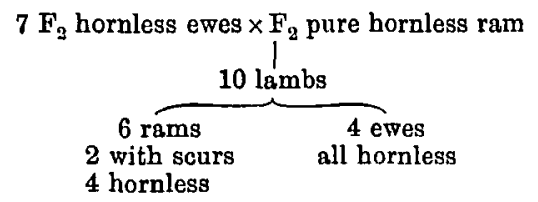

One or more of the $F_{2}$ ewes must have been heterozygous in order to have carried the scurs which appear in two of their progeny. Two more threw up scurs when two years old. The rest are still hornless. On the assumption that hornlessness is dominant in the female, hornless ewes in $F_{2}$ must be of two kinds, pure and impure as regards hornlessness.

Horned $F_{2}$ ewes. Of the three horned ewes which appeared in the second generation, one died when about six months old. The other two have both been tested by mating them with a Dorset horned ram.

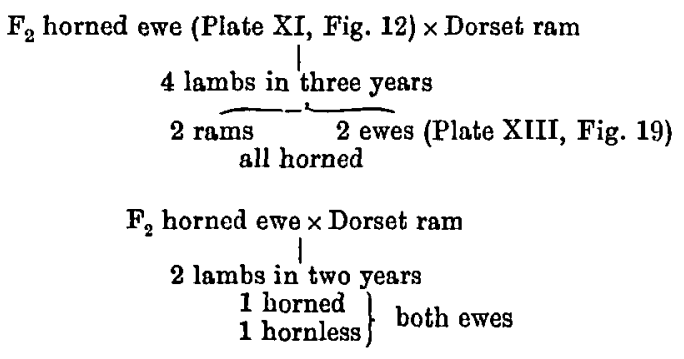

The first of the above ewes, having produced two ewe lambs both horned, is almost certainly pure horned, as she ought to be if horns are recessive in the ewe. The second, having produced a ewe lamb without horns, appears to be altogether abnormal. No explanation seems possible except that she was accidentally served by a hornless ram, and there is no reason to suspect that this took place-in fact every possible precaution was taken to prevent such an occurrence.

Speckled faced $F_{2}$ ram (Plate XI, Fig. 10). The following figures show the distribution of face colour in the progeny of this ram when mated with $\mathrm{F}_{1}$ ewes. The ram is the same one already tested for purity of hornlessness.

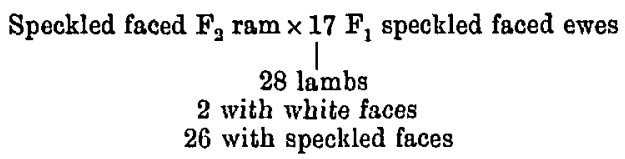




\section{Inheritance of Horns and Face Colour in Sheep}

Among the speckled faces were a few showing the same indications of pattern as those already described as occurring in $\mathrm{F}_{2}$. No black faces were obtained, otherwise the segregation was similar to that which took place in $\mathrm{F}_{2}$.

One of the white faced rams from this mating was kept for stock and tested for purity of face colour by mating with Dorset ewes. This was done as the white faced rams of $\mathrm{F}_{2}$ had been castrated owing to a misunderstanding with the shepherd.

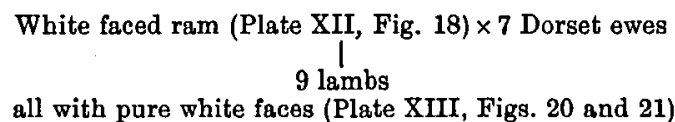

White faced animals which appear in the progeny of the mating of speckled faced parents appear to breed true to white face. It has not been possible up to the present to test the purity of any of the black faced animals.

Woolly and bare heads. In the second and succeeding generations the segregation of woolly and bare heads has been very marked. Examples are shown in Plate XIII, Figs. 22 and 23. Notes of these characters were not taken in the earlier stages of the experiment, so it is impossible to give definite numbers. It was noted that all the individuals of $F_{1}$ had more or less wool on the head. The number of animals with bare heads in $F_{2}$ and succeeding generations has been small. Absence of wool on the poll and face appears therefore to be a recessive character. This is supported by observations made on 98 lambs out of Suffolk ewes by an Oxford Down ram, all of which showed marked topknots.

\section{Summary and conclusions.}

1. As far as the characters under observation are concerned it is immaterial which way the cross is made. Reciprocally bred first crosses are identical.

2. The inheritance of horns is closely connected with sex. Large horns are dominant in the male, recessive in the female.

3. The meaning of scurs is not yet settled. Two kinds of scurs were observed, small round firmly attached knobs and thin loose scurs. The fact, which unfortunately was not observed until the later stages of the experiment, that the appearance of scurs is sometimes delayed until the animal is two years old, has given rise to an additional complication. 
4. A horned ram may be either pure horned or heterozygous as regards that character. His purity can readily be tested by mating with a number of horned ewes. If all his ram lambs are horved he is presumably pure, if any of them are hornless he is heterozygous.

5. A hornless ram must be pure hornless. His purity can be tested by mating with a number of pure hornless ewes, when all the progeny are found to be hornless.

6. A horned ewe must be pure horned. Her purity can be tested by mating her with a pure horned ram. All the ram lambs produced will be horned, for horns are dominant in the male. All the ewe lambs should be horned if she is pure. It may be several years before she bears euough ewe lambs to enable the experimenter to state with anything like certainty that she breeds true to horns. It is bere that the chief difficulty of working with large animals on Mendelian lines is found. The females produce only one or two young in the year, so that several years must elapse before a female can be thoroughly tested.

7. A hornless ewe may be either pure hornless or heterozygous. She can be tested by mating with a hornless ram. The same difficulty again arises, in fact it must always arise in the case of testing slow breeding animals. The males are readily tested, but the testing of the females is so slow that it must often be uncertain. 'I'his is the explanation of the common and very true statement that the way to improve a flock is to use good males. Males are readily tested and their purity as regards desirable characters is therefore very soon assured. Several generations may have been bred from a female, and her blood diffused through the flock, before the breeder can be sure that she breeds true to the type he wants.

8. The occasional occurrence of scurs in Suffolks already referred to is probably explained by the dominance of the hornless condition in the female. A hornless ewe may be heterozygous. This can only be found out by a breeding test, and may easily be overlooked in practice. Her progeny would then mix with the flock, and a sinall proportion of their ram lambs would produce scurs.

9. There is no dominance of white face over black or vice versá. The first cross as regards face colour is intermediate between the two parental types. Pure white and black fuces segregate in the second generation. The black face is not a simple character, since the number of speckled faces in $F_{2}$ is far too large, and the speckled faces include several distinct types of pattern. 


\section{Inheritance of Horns and Face Colour in Sheep}

10. Woolly and bare heads appear to be a pair of characters which blend in the first cross but segregate again in later generations.

11. A number of striking instances of recombination have been observed. For instance, horns, woolly poll and face, and black face are combined in the ewe, Plate XII, Fig. 15. She has been shown to breed true to horns, but her purity as regards woolliness and blackness of face has not as yet been tested. Another example is the ram shown in Plate XII, Fig. 18, which combines the bare head and hornless character of the Sulfolks with the white fuce of the Dorsets.

12. Finally attention should once more be drawn to the difficulties of experimental breeding with large animals. The slowness and lack of certainty in testing the females, and the troubles arising therefrom, have. already been dilated upon. Another difficulty is the complicated nature of what might have been hoped to be simple characters. Points of economic importance such as would be likely to appeal to the butcher, the dealer or the wool merchant, are hardly likely to turn out less complicated than horns or face colour. The experiments described above have suffered greatly from the fact that it was impossible with the comparatively small area available to keep more than a very small proportion of the rams until they were old enough to show all their characters. The unsatisfactory state of the evidence given above as to the question of scurs is in part due to this. It is however a difficulty which would disappear with increased resources. 


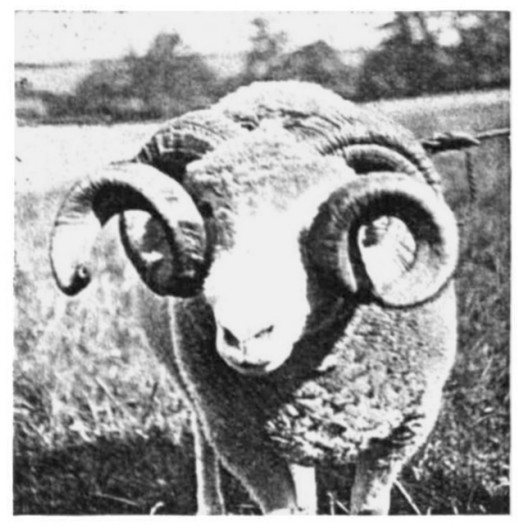

Fig. I.

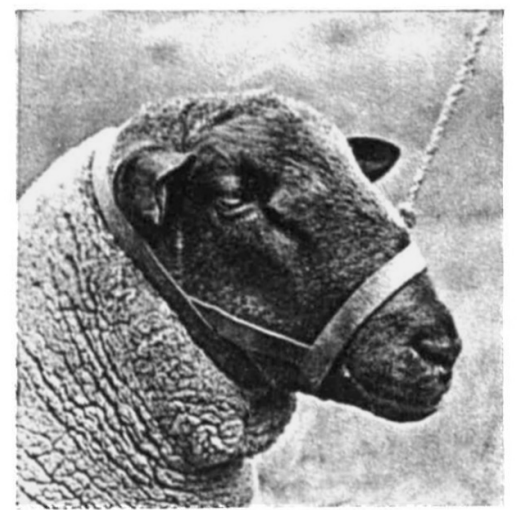

Fig. 3.

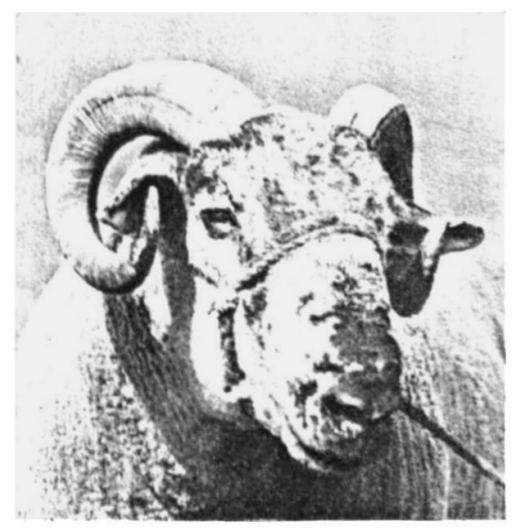

Fig. 5.

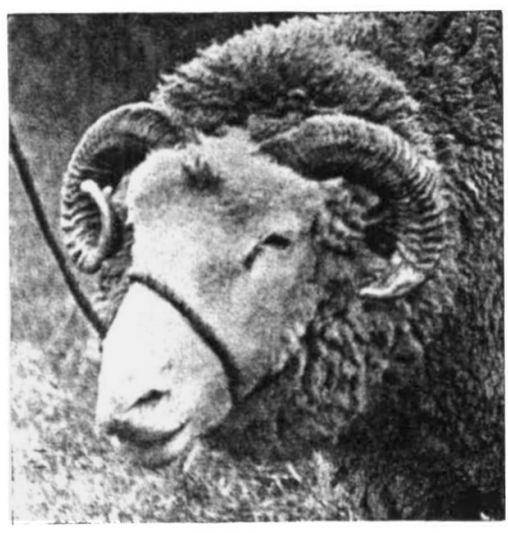

Fig. 2.

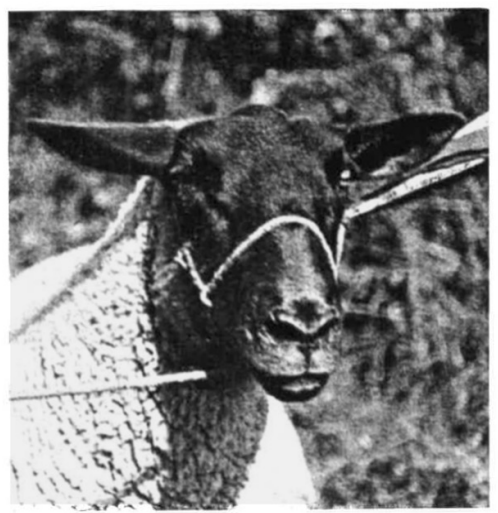

Fig. 4.

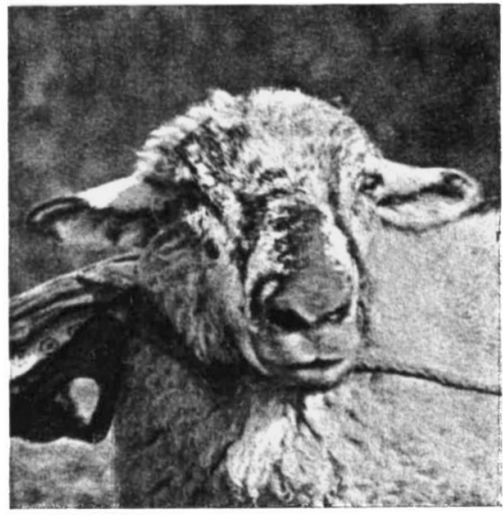

Fig. 6. 


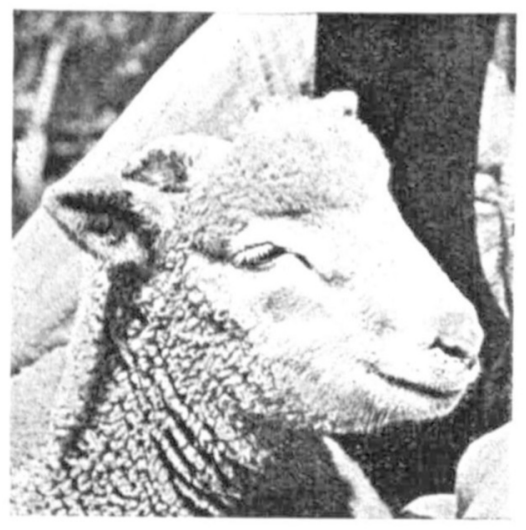

Fig. 13.

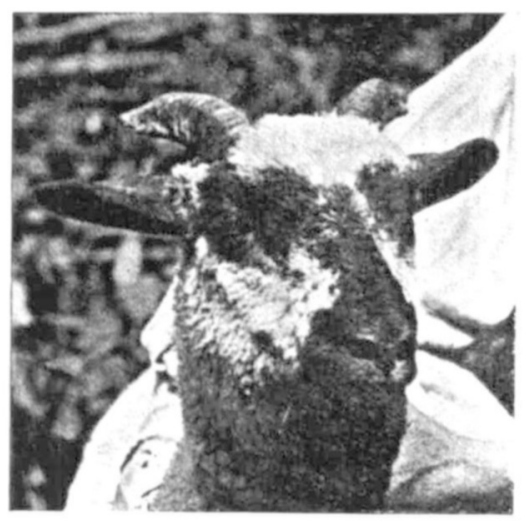

Fig. 15.

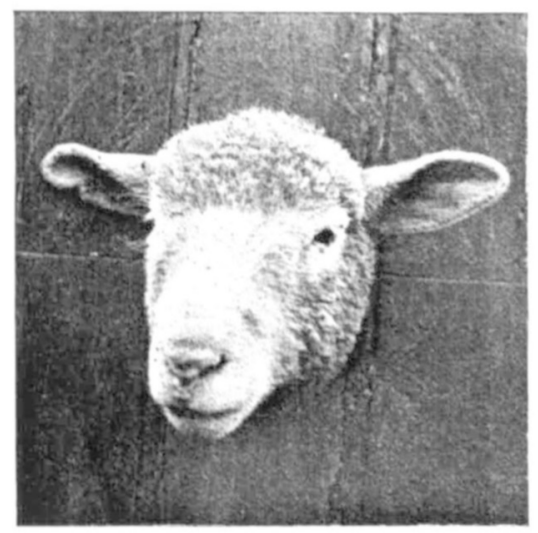

Fig. 17.

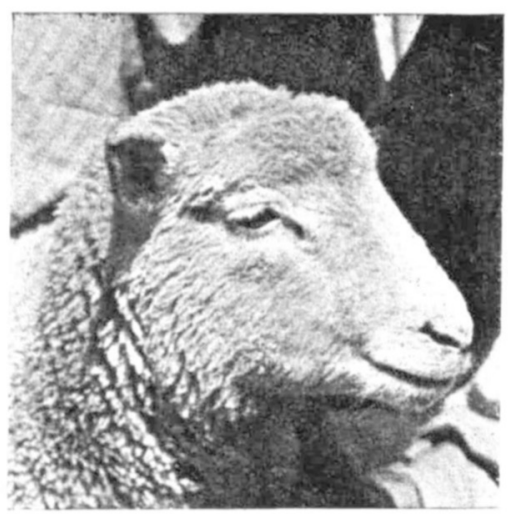

Fig. 14.

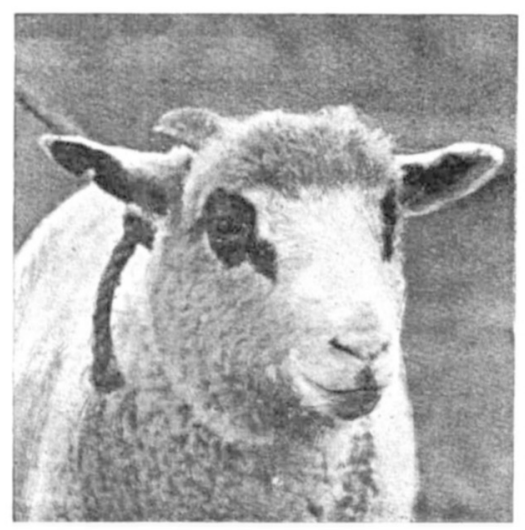

Fig. 16.

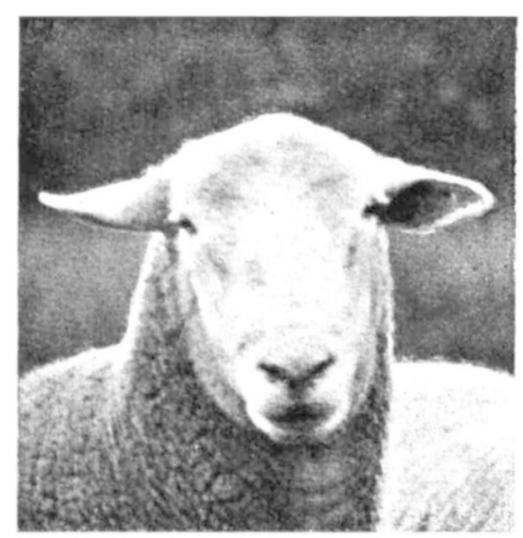

Fig. 18. 


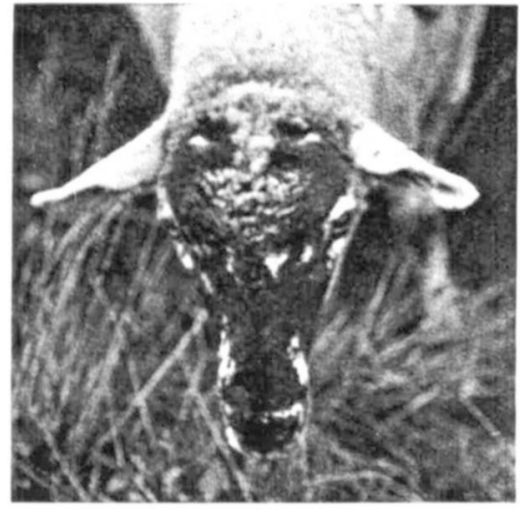

Fig. 7.

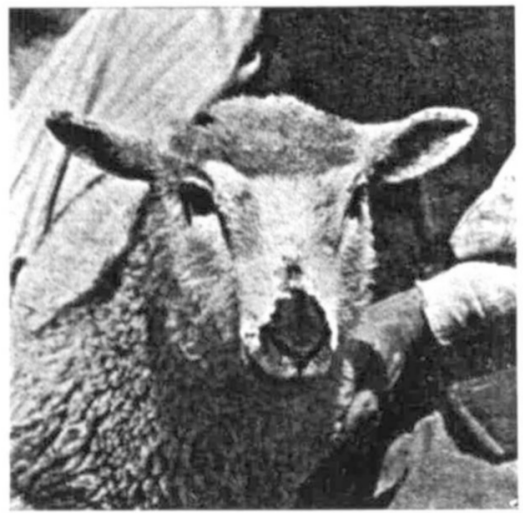

Fig. 9.

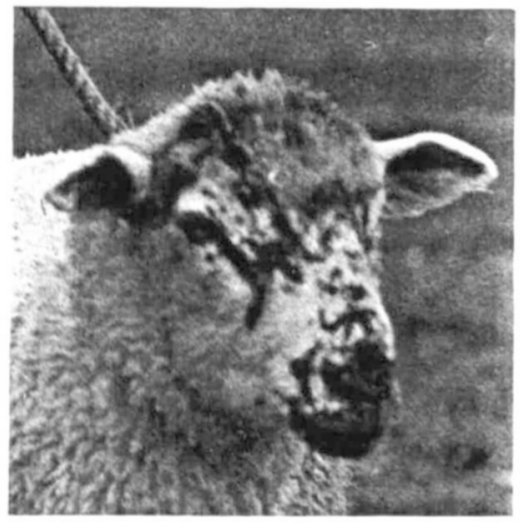

Fig. 11.

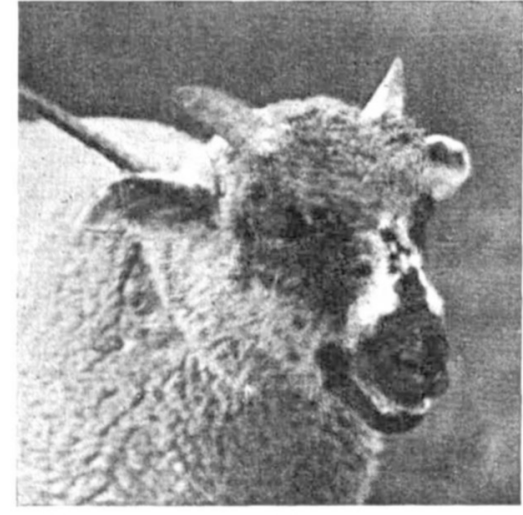

Fig. 8 .

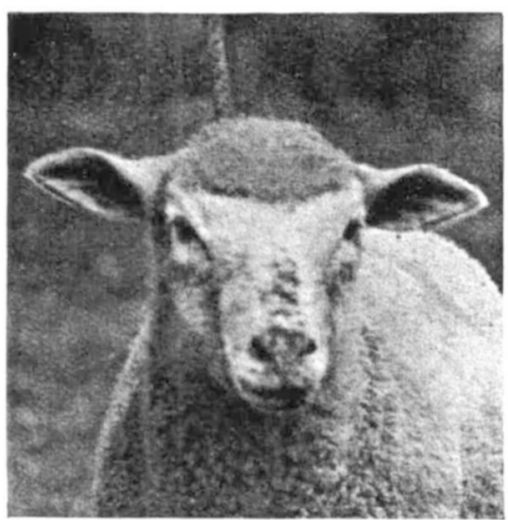

Fig. 10 .

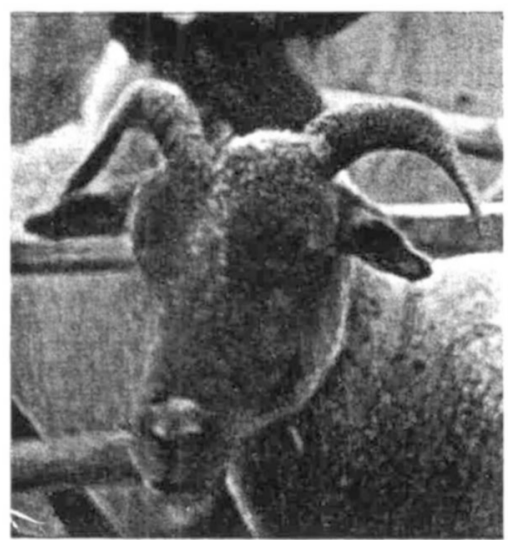

Fig. 12. 


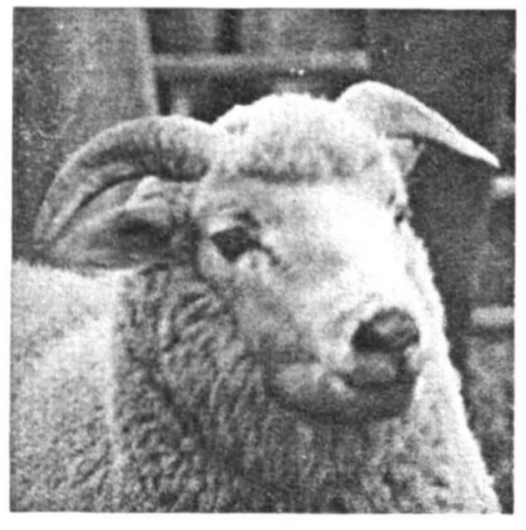

Fig. 19.

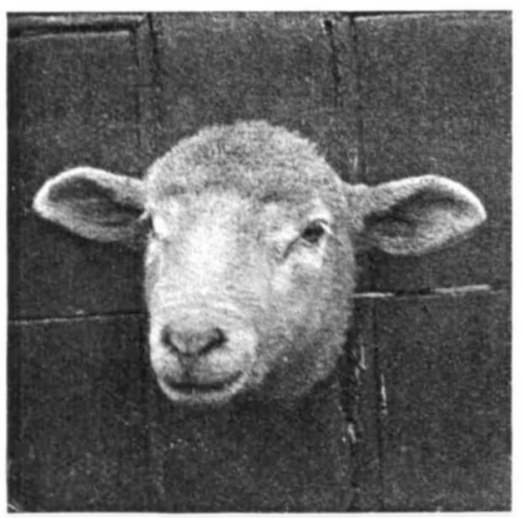

Fig. 21.

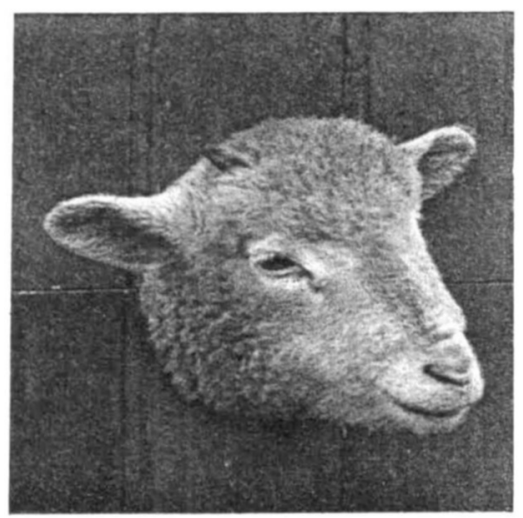

Fig. 20.

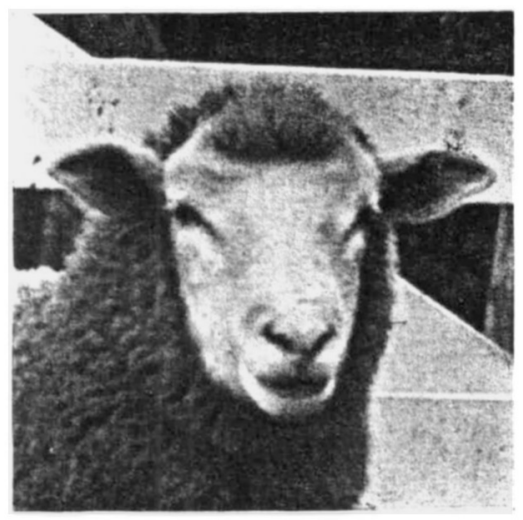

Fig. 22.

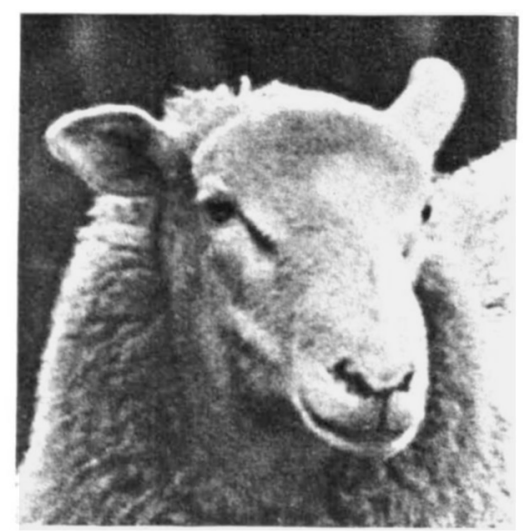

Fig. 23. 